\title{
Aux origines idédogiques de la Révolution, journaux et pamphlets à Rennes (1788-1789)
}

Jean-Paul Bertaud

\section{(2) OpenEdition \\ 1 Journals}

Édition électronique

URL : https://journals.openedition.org/ahrf/1147

DOI : 10.4000/ahrf.1147

ISSN : 1952-403X

Éditeur :

Armand Colin, Société des études robespierristes

Édition imprimée

Date de publication : 1 septembre 2001

Pagination : 138

ISSN : 0003-4436

\section{Référence électronique}

Jean-Paul Bertaud, « Aux origines idédogiques de la Révolution, journaux et pamphlets à Rennes

(1788-1789) », Annales historiques de la Révolution française [En ligne], 325 | juillet-septembre 2001, mis en ligne le 10 avril 2006, consulté le 24 avril 2022. URL : http://journals.openedition.org/ahrf/1147 ;

DOI : https://doi.org/10.4000/ahrf.1147

Ce document a été généré automatiquement le 24 avril 2022

Tous droits réservés 


\title{
Aux origines idédogiques de la Révolution, journaux et pamphlets à Rennes (1788-1789)
}

\author{
Jean-Paul Bertaud
}

\section{RÉFÉRENCE}

Aux origines idédogiques de la Révolution, journaux et pamphlets à Rennes (1788-1789), textes présentés par Roger Dupuy, Presses universitaires de Rennes, 2000, 500 pages, 185F $(28,20 \mathrm{E})$.

16 novembre 1788: à Versailles, l'assemblée des notables discute de la forme des futurs États généraux: le nombre des députés du Tiers État sera-t-il doublé et le vote se fera-t-il par tête et non par ordre? L'agitation au sujet de la réforme des États généraux gagne tout le pays. À Rennes, elle est d'autant plus vive que les États de la province doivent se réunir en décembre.

2 Les avocats et les édiles rennais rejoignent les armateurs et les négociants nantais pour dénoncer l'injustice de la représentation du Tiers État breton encore plus scandaleuse que celle imposée par l'ancienne réglementation des États généraux du royaume. La noblesse ne veut rien entendre et le Parlement de Rennes condamne les assemblées réunies par les réformateurs puis menace ceux-ci de prison. Paraît alors La Sentinelle du Peuple, un pamphlet qui dénonce l'archaïsme de l'aristocratie. La rumeur publique l'attribue à Voiney. Janvier 1789: les États de la province se réunissent et des affrontements ont lieu dans les rues et les cafés avoisinants: étudiants en droit contre aristocrates. Ce n'est plus un pamphlet qui paraît alors mais un journal, Le Héraut de la Nation. Édité chaque semaine, il paraîtra jusqu'à la fin du mois de juin 1789. Se présentant comme l'expression d'un club patriote, confiant dans la toute-puissance de l'opinion publique éclairée, le journal rejette le privilège aristocratique, se veut organe d'information sur les débats de la «Diète bretonne», «aurore des États généraux» mais, 
«Héraut de la Nation», marque sa volonté d'élargir son propos à tous les problèmes politiques du royaume. Le journal sera un laboratoire d'idées.

3 On doit remercier R.Dupuy de nous donner ici les cinq numéros de la Sentinelle du Peuple et de ses imitations ainsi que les 63 numéros du Héraut de la Nation. La publication de ces feuilles est accompagnée d'une introduction qui situe parfaitement le contexte historique et est enrichie d'une présentation des journaux et de leurs auteurs. Ainsi sont mises à la disposition des historiens de la presse une source indispensable et à la réflexion des historiens de la culture politique de la Révolution une manne de textes. 